\title{
Grade control and segregation at New Gold's New Afton block cave operation, Kamloops, British Columbia
}

\author{
MG Henning New Gold Inc., Canada
}

\begin{abstract}
New Gold's New Afton Cu-Au-Ag block cave mine is located near Kamloops, British Columbia and is composed of four production blocks situated along the deposit plunge. As a result of mineralisation contacts and geometry, certain production drawpoints are designed in waste or low-grade ore targeting higher column ore. When underground production is outperforming milling rates, the operation yields the ability to segregate waste and intermediate grade (IG) material for stockpiling. The benefits of stockpiling waste and IG include increased metal production, as well as lowering both process water demand and tailings storage requirements. Continued studies are ongoing to further refine and optimise segregation efficiencies at the New Afton mine and include live belt copper scanning technology combined with an automated diverter. The goal is to minimise rehandling, reduce waste/intermediate grade/ore blending and further maximise profits.
\end{abstract}

Keywords: segregation, conveyor analyser, production, cash flow

\section{Introduction}

The mine is located approximately $13 \mathrm{~km}$ west of Kamloops, British Columbia at the site of the historic Afton Mine, a previous operation of Teck Resources Limited. The New Afton site currently includes two open pits (Afton and Pothook), underground workings, historic support facilities, a new mill concentrator and a tailings storage facility (TSF).

Production blocks are situated along the deposit plunge with an east-west orientation. Production levels are shallowest in the East Cave where the extraction level is $350 \mathrm{~m}$ beneath Afton open pit followed by West, B3 and C-zone Caves located at depths of 600, 720 and 1,200 m, respectively (Figure 1). Caving was initiated in the West Cave and commercial production commenced in July 2012 with a designed mill throughput of $11,000 \mathrm{tpd}$. Over the past five years of optimisation, the mill has expanded to 15,000 tpd. By the end of 2017, New Afton had produced approximately $452.8 \mathrm{M}$ pounds of copper, 522,225 ounces of gold and $1.4 \mathrm{M}$ ounces of silver from the East and West Caves (the A-zone). The 2017 mineral reserve estimate reported the following:

- A-zone and B-zone contain $28.1 \mathrm{Mt}$ grading $0.51 \mathrm{~g} / \mathrm{t} \mathrm{Au}, 2.2 \mathrm{~g} / \mathrm{t} \mathrm{Ag}$ and $0.79 \% \mathrm{Cu}$.

- C-zone contains $26.7 \mathrm{Mt}$ grading $0.72 \mathrm{~g} / \mathrm{t} \mathrm{Au}, 1.8 \mathrm{~g} / \mathrm{t} \mathrm{Ag}$ and $0.77 \% \mathrm{Cu}$.

The ore geometry required particular waste/intermediate grade (IG) drawpoints (DPs) to be blasted to target higher ore in the column. Perimeter waste DPs with no high-column ore are drawn to a minimum of $50 \mathrm{~m}$ height of draw (HOD) to maintain minimum cave widths. The 2005 feasibility study stated that all conveyed material would be processed and stored in the TSF. In reality, waste segregation began after steady-state caving was achieved and production rates exceeded mill throughput. Further underground material handling efficiencies led to increased segregation capacity in 2015, giving rise to the start of the IG segregation and stockpiling program at a rate of 2,000-5,000 tpd.

Copper has the least amount of variability both laterally and vertically across the deposit. This paper will focus solely on copper grade for tracking waste/IG/ore segregation classification, although, in practice, if a detailed analysis is required, a net smelter return is used. 
Material classification is determined through production sampling, demarcated on the daily draw call, and selectively conveyed in batches. Waste and intermediate grades are diverted off the conveyor prior to the live pile and trucked to their designated dump locations. Processing of the planned $2 \mathrm{Mt}$ intermediate stockpile is planned either at the end of mine life or consumed during production gaps between lifts; this helps to ensure further operational flexibility.

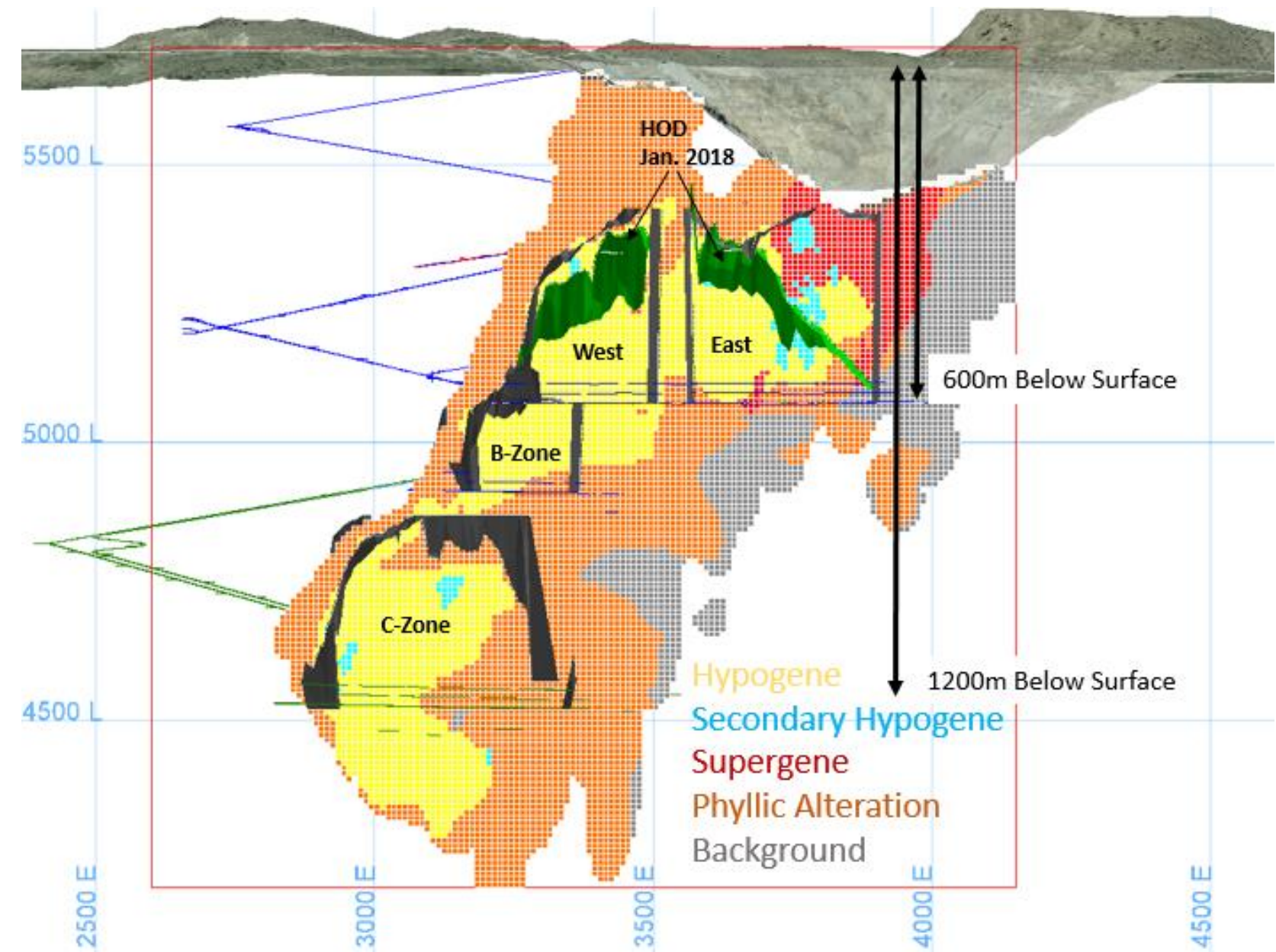

Figure 1 New Afton ore geometry plunge, ore type orientation, phyllic altered pyritic halo, mine layout and production block locations. HOD $=$ height of draw

\section{$2 \quad$ Geological setting}

New Afton is one of a group of alkalic porphyry Cu-Au deposits found in a late Triassic monzodiorite belt and coeval Triassic volcanic strata of the Nicola Group in Quesnel terrane of the Canadian Cordillera (Hall \& May 2013). The New Afton deposit shares geological similarities to a series of alkalic $\mathrm{Cu}-\mathrm{Au}$ porphyries situated south-to-north through the province of British Columbia such as Copper Mountain, Mount Polly, Mount Milligan, Kemess and Galore Creek. At New Afton, mineralisation is mainly hosted within crystalline and polymictic fragmental volcanics belonging to the Triassic Nicola Formation and lesser monolithic intrusive breccias consolidated into one lithology informally referred to as 'BXF' (Lipske \& Wade 2014).

Mineralisation is associated with structurally controlled magmatic emplacement derived from an active period of subduction. A late-phased monzonite intrusive stock-dyke swarm is thought to be the causative intrusive and is controlled by the Hanging Wall Fault and picrite along the southern margin of the deposit. The monzonite unit is generally weakly mineralised around the outer extents and has a barren core. The deposit is overprinted by younger tectonic deformation resulting in a varying degree of alteration, ranging from clay gouge fault infilling to brittle fracturing increasing rock mass porosity. Structural controls generate complexity to the deposit grade, mineralogy, distribution and geometry. 


\section{$2.1 \quad$ Ore types}

New Afton contains three main ore types: hypogene, secondary hypogene, and supergene. Hypogene mineralisation was the first emplacement of ore, associated with potassic alteration (biotite and microcline), estimated to be 200-205 Ma (Logan et al. 2007) and dominated by disseminated and fracture-filled chalcopyrite with lesser bornite and pyrite. The secondary hypogene phase of mineralisation is a structurally controlled fluid event supplying a minor amount of additional metal and causing a metasomatic reaction with earlier hypogene ore. The result is narrow zones of mineralisation containing disseminated to blebby fracture-filled bornite, and tennentite/tetrahedrite with remnant chalcopyrite. The quartz-dolomite-kaolinite alteration assemblage that hosts secondary hypogene mineralisation was dated using $\mathrm{K}-\mathrm{Ar}$ whole rock analysis and returned an age of $155 \mathrm{Ma}$. Supergene mineralisation is marked by iron oxide alteration, native copper $+/$ - chalcocite and lesser remnant primary copper sulphides. It is confined to an area of high structural deformation where the rock mass is highly fractured giving rise to meteoric fluid conductivity. Native copper plates and fills fracture as dendritic leaves with thicknesses of $<1 \mathrm{~cm}$. On the eastern side of the deposit, supergene mineralisation is common at the East Cave production footprint $600 \mathrm{~m}$ below surface. Figure 1 illustrates the crosscutting-overprint relationship of secondary hypogene on primary hypogene, and how the supergene zone takes on a tooth-like expression as enriched oxygenated fluids are contained within the structurally weak rock mass.

\subsection{Copper grade distribution}

The causative intrusion takes on a dyke-like expression; it is a relatively small magma source, therefore, the zone of mineralisation is contained within a tight envelop proximal to the heat source. This scenario theorises that mineralisation was emplaced in front of the rising magma with the monzonite displacing mineralisation. As seen in Figure 1, the deposit is also surrounded by phyllic alteration marked by pyrite, kaolinite and dolomite alteration. Textures within the rock record suggest that this phase of alteration supersedes hypogene mineralisation and may have stripped or overprinted primary mineralisation. These attributes give rise to sharp $(3-5 \mathrm{~m})$ copper grade boundaries between high grade $(>0.8 \% \mathrm{Cu})$ and waste grade $(<0.20 \% \mathrm{Cu})$. This differs from traditional porphyry where grades gradually zone from high grade to no grade.

The highest grades correlate to areas where there is the presence of secondary hypogene fluid enrichment. Figure 2 illustrates the highest grades in the East Cave and the abrupt contacts following the intrusive plunge. The A-zone level was divided into two caves (East and West Caves) because of a sub-economic pillar between the two; barren monzonite and phyllic alteration merge causing mineralisation to pinch out.

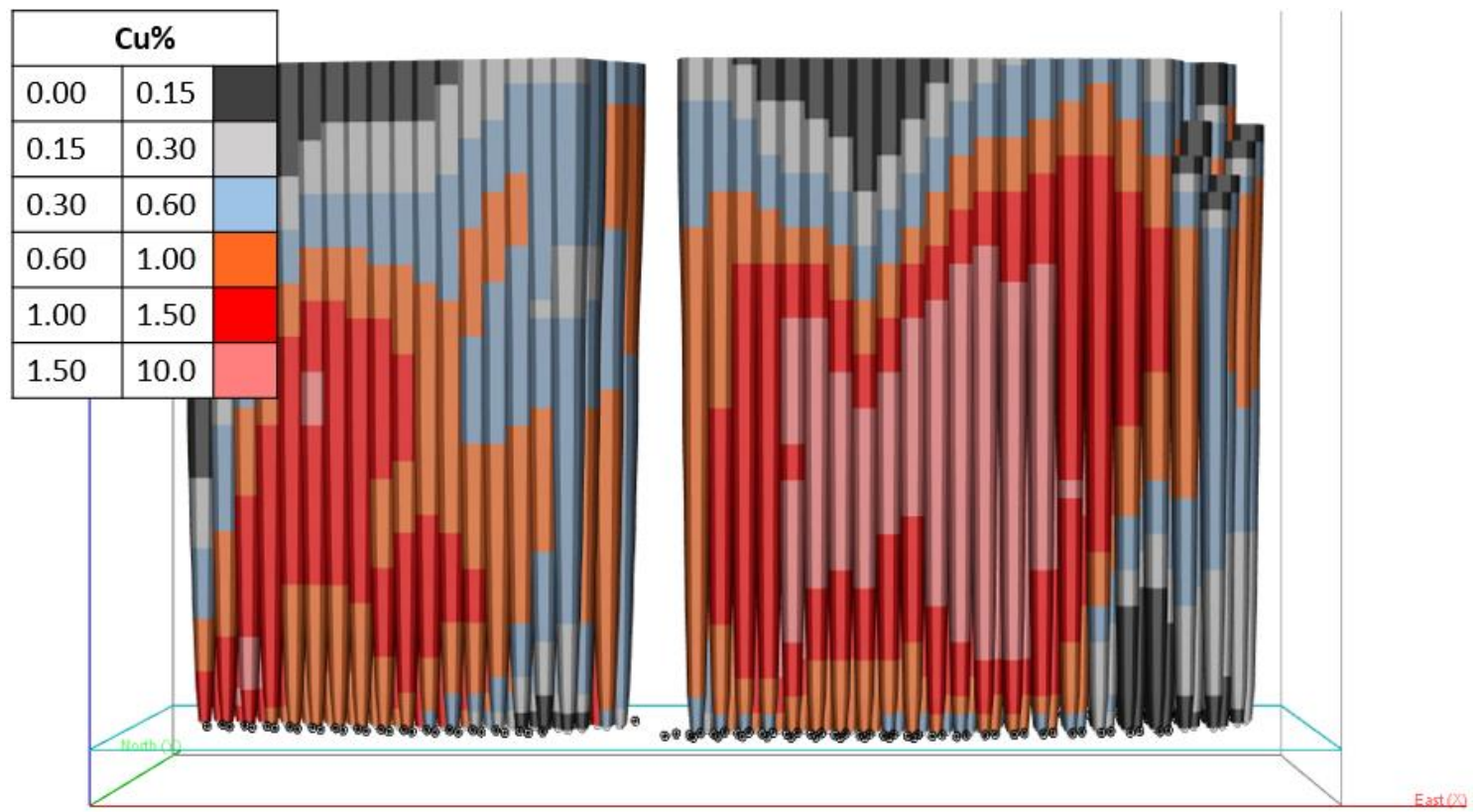

Figure 2 Centrally drawn long section through the West and East Caves showing an isotropic distribution of copper 


\section{$3 \quad$ Production sampling}

When considering material segregation, production sampling is critical for monitoring grades during cave drawdown. The New Afton sampling program was originally designed for grade control, resource estimation and mill reconciliations. Once waste and IG segregation began, sampling became a key component of material tracking for waste/IG/ore classification. Sample tonnage frequencies range from one muck sample every 240-960 t, depending on material classification needs, ore variability and DP closure requirements. Results are also used for mine-mill reconciliation, draw control grade planning and PCBC (Dassault Systèmes 2018) model calibration.

\subsection{Sample generation}

Production samples are issued to scoop operators and are collected across the muck pile or across the scoop bucket targeting a weight of 4-6 kg and containing $<10 \mathrm{~cm}$ rock fragments. Due to the nature of composite grab samples, results have a high degree of grade variability. Possible reasons for sample variability result from a combination of cave mixing, heterogeneity of mineralisation or quality/consistency of sampling practices. The number of samples per month range from 5-20 for each active DP and a monthly weighted average is calculated which smooths variability noise.

\subsection{Grade variability}

The E44S copper grade profile (Figure 3) is an example of how a DP is planned in waste and transitions to high-grade mineralisation within two months of production. There are also a few examples of highly variable copper results where two neighbouring samples can differ by $>1.5 \% \mathrm{Cu}$.
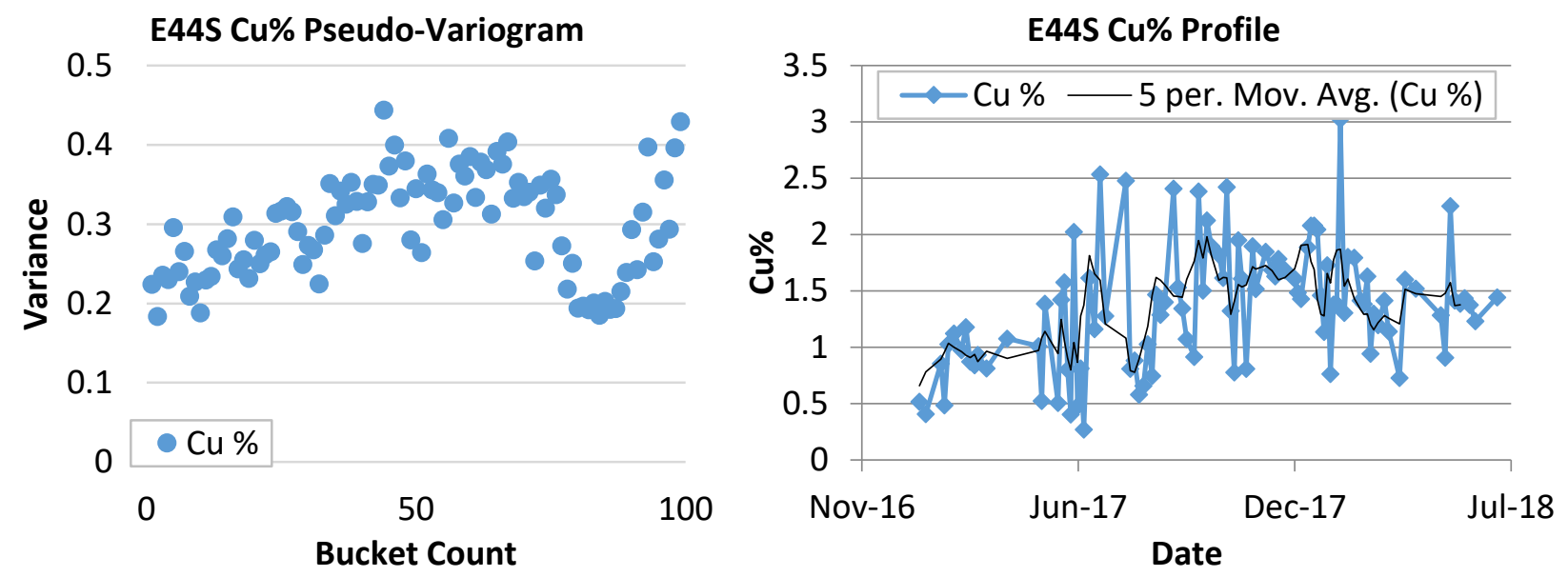

Figure 3 Copper grade profile and viability plot of E44S of the recent 100 sample results

An application of variance is used to measure data confidence in the recent 100 copper results. The generation of a pseudo-variogram assists in the determination of the confidence value indicating when the next production sample should be issued without losing data integrity. The linear trend in the above pseudo-variogram displays confidence with up to 80 buckets and is correlated to the last six months of sampling results with a lower average copper variance of $0.25 \% \mathrm{Cu}$. 


\subsection{Sample frequency}

To reduce sampling cost and time requirements of production operators while also maintaining data integrity, an adjusted sample frequency program was established. Increased data points are required where DPs are changing material classification, experiencing unplanned dilution or high variability and approaching their exhaustion height. Production tonnes translate into vertical HOD by using a bucket factor of $8.1 \mathrm{t}$ per bucket and a draw cone radius of $8 \mathrm{~m}$ at $120 \mathrm{~m}$ HOD. Therefore, sample bucket frequency, production HOD, tonnes and buckets can be interchanged (Table 1).

Table 1 Sample frequencies represented in HOD, buckets and tonnes

\begin{tabular}{lll}
\hline Frequency & HOD $(\mathbf{m})$ & Tonnes \\
\hline $1: 30$ & 0.5 & 240 \\
$1: 60$ & 1 & 480 \\
$1: 90$ & 1.5 & 724 \\
$1: 120$ & 2 & 965 \\
$1,000,000$ & - & - \\
\hline
\end{tabular}

The frequency distribution varies across the production footprint; low sample frequencies are centralised within the cave footprint and higher frequencies are located around the edge and where younger DPs are constructed in waste/IG grades. The colour classification in Figure 4 reveals the pattern. However, the dark blue boxes $(1: 1,000,000)$ identify DPs that are temporarily closed (e.g. for rehabilitation) but will eventually enter back into production.

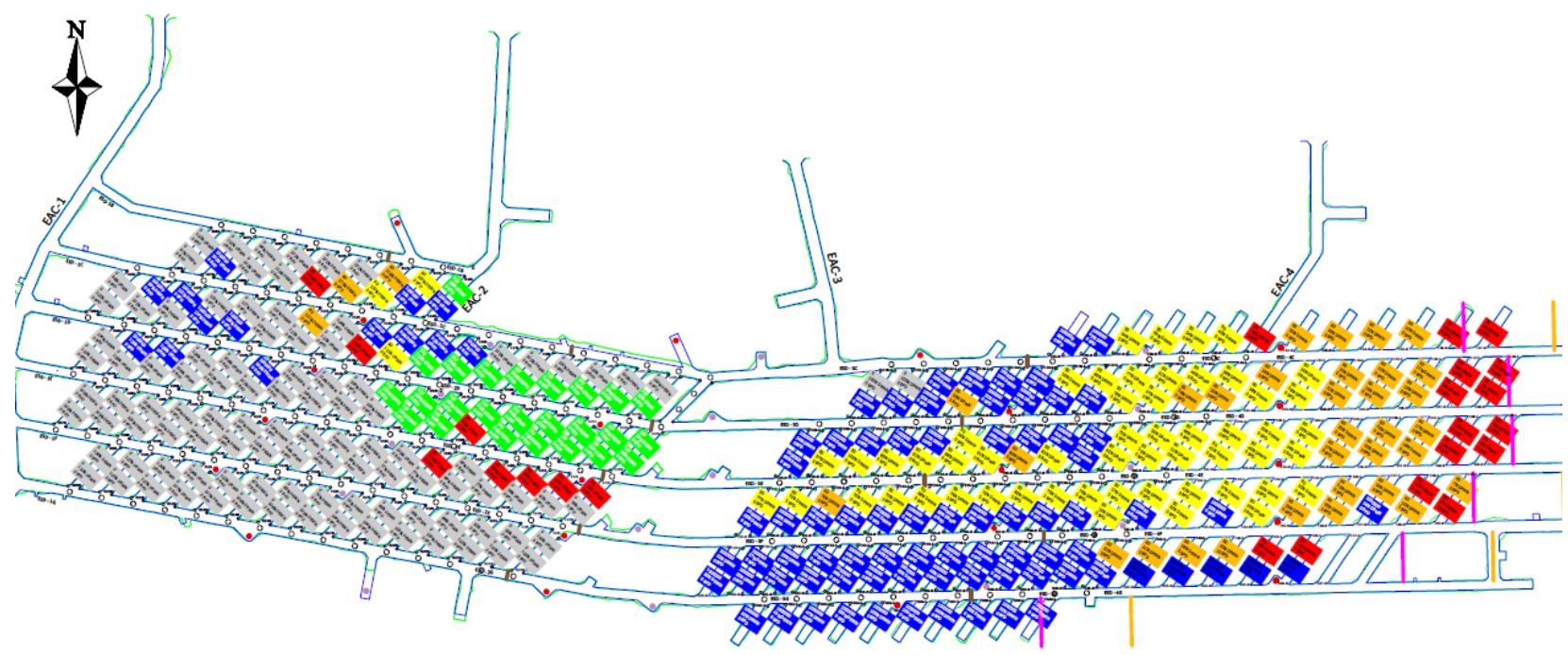

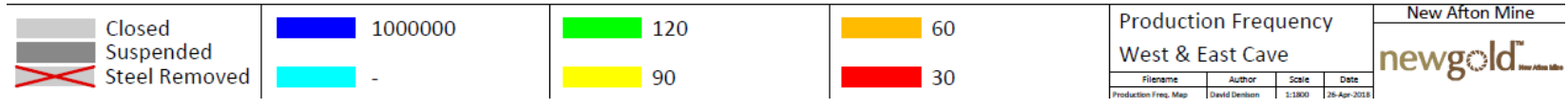

Figure 4 Sample frequency map showing variable requirements across the production footprint in buckets per sample 


\section{$4 \quad$ Material handling}

Extraction level production utilises six-yard scoop trams (scoops) which dump into equally distributed ore passes along the five strike drives. Material is picked up at the bottom of the ore passes by 11-yard scoops, dumped into $45 \mathrm{t}$ trucks and hauled to the north centrally located gyratory crusher. Based on a rolling 30-day average grade, each DP is classified into one of the following grade categories: ore $>0.30 \% \mathrm{Cu}$, IG $<0.30 \% \mathrm{Cu}$, or waste $<0.15 \% \mathrm{Cu}$.

Technical services and mine operations departments generate a weekly convey strategy, balancing multiple factors including mill feed, cave-induced stresses, depletion strategy and development material movements. To maximise tonnage efficiencies, material is conveyed in batches. When there is limited daily tonnage for a particular class of waste or IG, the scheduled batch is adjusted to every three to five days, targeting 2,000-3,000 t per batch. For this scenario, DPs continue to be mined daily but are stored within their designated storage bay along the haulage level (refer to the three large red circles in Figure 5 locating the $5,000 \mathrm{t}$ storage bays). Storage bay material is combined with production level material, thus maximising conveyor run time. When switching between ore and waste/IG class types, operators empty specific orepasses, calculate gyratory ore bin drawdown, and then generate a small belt load gap at the apron feeder. The gap on the belt signals a change in material type and denotes when the plow is to be activated. Waste and IG classes share the same drop pad which is located prior to the live pile. Therefore, the drop pad needs to be cleared before a waste/IG drop is made.

The 4th type of segregated material comes from localised DPs which contain high amounts of fault-derived clay gouge combined with moderate moisture levels ranging from $3-8 \%$; this clay gouge tends to cause conveyor chute plugging and numerous crush and conveyor system problems. The most effective way to increase conveyor availability is to isolate this wet clay-rich material from the crusher and conveyor system. Segregating and trucking 300-500 tpd of wet clay material away from the conveyor system allows the mine to maintain production rates.

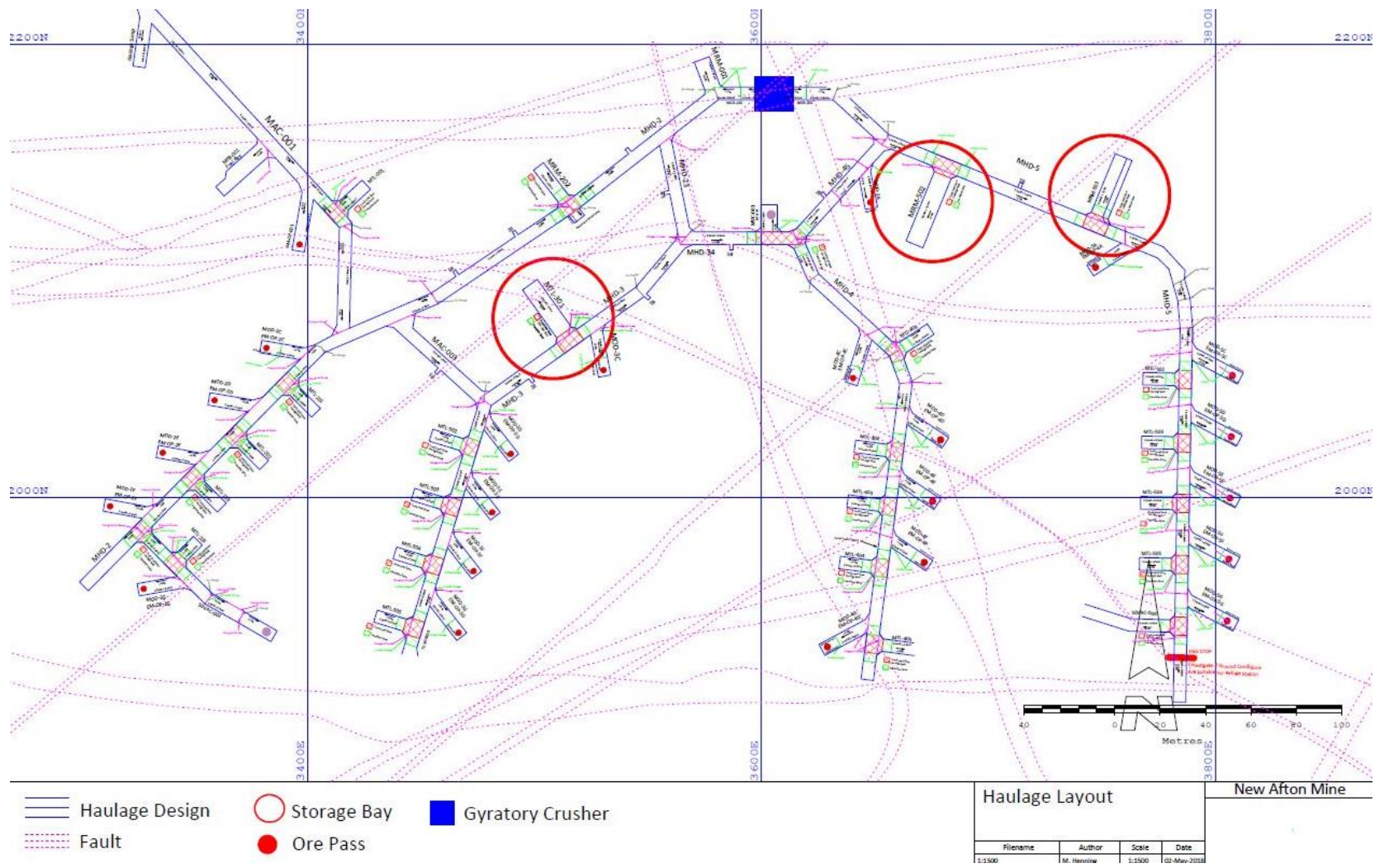

Figure 5 Haulage level layout 


\section{$5 \quad$ Live conveyor scanner}

In order to further refine New Afton's bulk-sorting practices, a live stream belt analyser was installed late in 2017. The instrument uses a technique known as prompt gamma neutron activation analyses (PGNAA). As the energy source passes through the conveyed material, detectors estimate a copper grade. An average copper grade is generated every 30 seconds which represents 8-10 t. Upgrades to the diversion plow were completed early in 2018 allowing for live activation to occur without damaging infrastructure. The upgrade includes an electrical communication process which ties analyser results to plow activation automating bulk diversion segregation. Figure 6 illustrates a display from the ore scanner output showing copper variability during an average production shift; note the gradual copper grade transitions between ore and IG classification type and the existence of isolated lows within the ore feed grade. By implementing automated technologies, segregation quality and volumes will increase, thereby generating additional revenue. The system is currently being calibrated and the goal is to eliminate lost metal to the waste pile, waste/IG from entering the mill feed, and waste from entering the IG pile.

\section{Scantech Ore Scanner Results Sun Mar 252018}

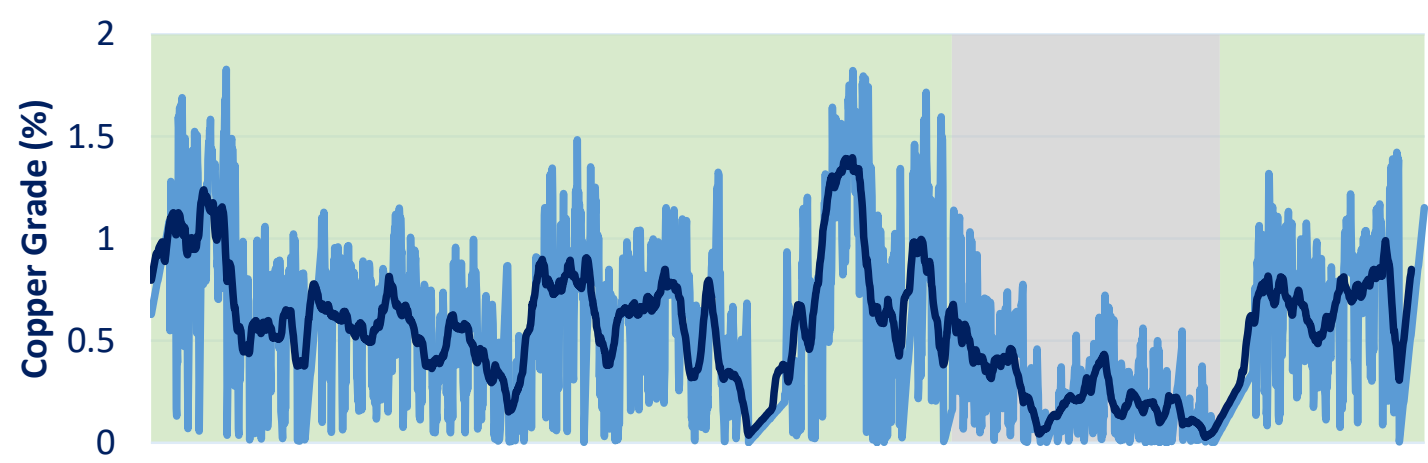

07080910111213141516171819202122230001020304050607 Time (hr.)

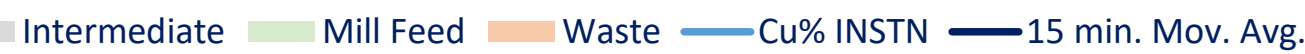

Figure 6 Copper readings from the belt analyser for a typical production shift with IG segregation

\section{Economic justification}

The economic return is generated by removing waste and IG material from the ore stream, resulting in increased metal production. Profits generated from increasing head grades can be split into the following two components: contained metal and recoveries. Although the majority of value comes from increases in contained metal, a small portion is realised from increased recoveries. The formula below demonstrates how a small change in copper grade can generate CAD 450,000 per operating month where the average throughput is $\sim 450,000 \mathrm{t}$. Other attributes providing economic gain derived from not processing waste are reduced plant, TSF construction and water consumption costs.

$$
\begin{gathered}
\text { Value }=\text { grade increase } * \text { conversion factor } * \text { tonnes } * \text { recovery } * \text { Cu price } / \mathrm{lb} \\
=0.02 \% \mathrm{Cu} * 22.04 * 450,000 * 0.82 \% * \mathrm{CAD} 3.00 / \mathrm{lb} \\
=\mathrm{CAD} 487,965
\end{gathered}
$$

Considering the value gained from increased head grades and cost of rehandling, segregation adds between CAD 25 and CAD 30/t of waste/IG that is removed from the mill feed. Using an average of CAD 27/t, Figure 7 shows a simple representation of increased profits/month from tonnes segregated since the program started in 2014. 


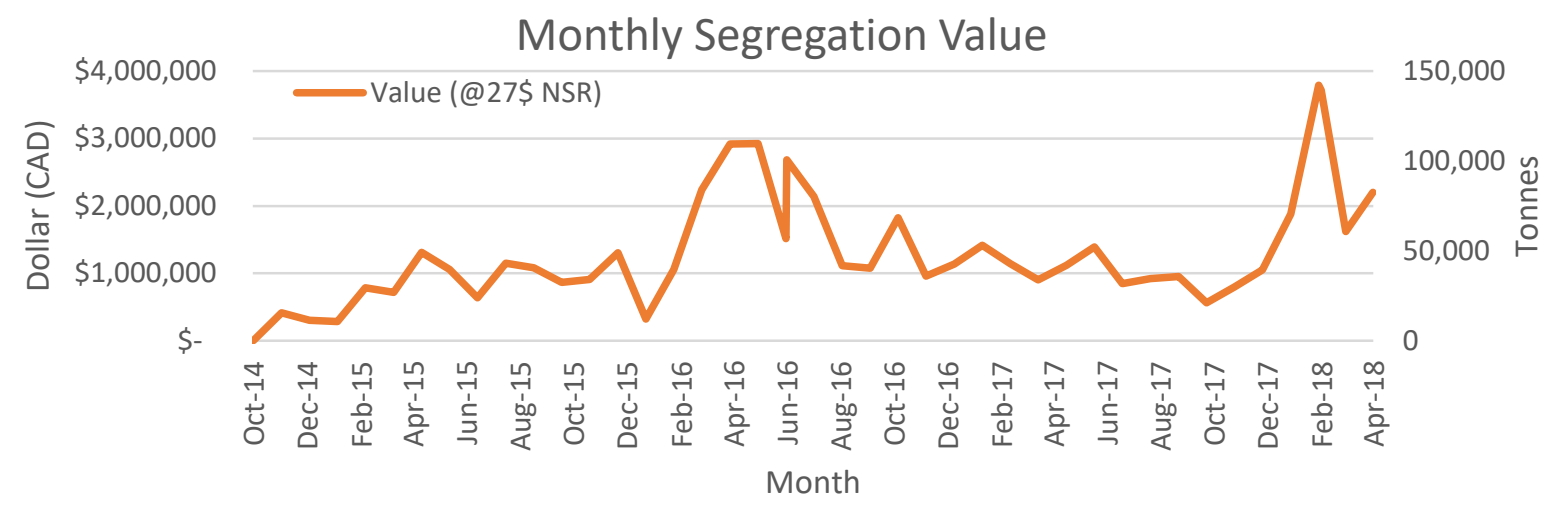

Figure 7 Monthly tonnage segregated and estimated value of segregation efforts

\section{Conclusion}

Bulk-sorting segregation is an obtainable approach at the New Afton mine that produces additional revenue with a small effort. The geology and geometry of the deposit construct a scenario that is ideal for bulk-sorting segregation because material can be classified into discrete waste/IG/ore classifications. Additionally, a result of increased material handling capacity over milling rates allows for $10-20 \%$ of the lowest grades to be removed from the mill feed. By generating a small increase in feed grade $(0.02-0.05 \% \mathrm{Cu})$, contained metal production gives rise to over CAD 500,000 in additional revenue per operating month.

Automation of an online grade analyser further adds to production efficiencies by reducing rehandling costs, increasing conveyor utilisation and increasing segregation quality. New Afton is a small block cave mine in comparison to the large operators such as Grasberg $(200,000+t p d)$ and El Teniente $(130,000+t p d)$ mines, but it is a profitable operation which provides a steady cash flow to New Gold. Due to the scale of the operation, small changes in process flow can generate positive outcomes.

\section{Acknowledgement}

I have the upmost appreciation for my family; many thanks for the years of support enabling me to follow my dreams. The topics summarised in this paper would not have been possible without the help of the entire team. Special thanks go to Jane McCaw for proofing this paper and managing geological datasets and to our underground beat geologists Nimmi Dhadwal and Dave Hamilton, who are the eyes on the ground making segregation possible. Thank you Dave Denison for all your efforts keeping track of draw changes and material movements. Over the years, I have worked with many talented exploration geologists and enjoyed countless discussions with Brian Bower, Richard Hall, Joanna Lipske and Devin Wade trying to untangle the geological sequence of the New Afton deposit. New Afton is my second family and for that, I am grateful.

\section{References}

Dassault Systèmes 2018, PCBC, computer software, Dassault Systèmes, Paris, https://www.3ds.com/products-services/geovia/ products/pcbc/

Hall, R \& May, B 2013, 'Geology of the New Afton porphyry copper-gold deposit, Kamloops, British Columbia', in JM Logan \& TG Schroeter (eds), Canada Society of Economic Geologists Field Trip Guidebook, Series 43, pp. 117-128.

Lipske, J \& Wade, W 2014, Geological Model of the New Afton Copper and Gold Deposit, British Columbia, internal report, New Gold Inc., Vancouver.

Logan, JM, Mihalynuk, MG, Ullrich, T \& Friedman, RM 2007, 'U-Pb ages of intrusive rocks and ${ }^{40} \mathrm{Ar} /{ }^{39} \mathrm{Ar}$ plateau ages of copper-gold-silver mineralization associated with alkaline intrusive centres at Mount Polley and the Iron Mask batholith, southern and central British Columbia', Geological Fieldwork 2006, Ministry of Energy, Mines and Petroleum Resources, Vancouver, paper 2007-1, pp. 93-116. 